\title{
Research Article \\ Effect of Gas Flowrate on Nucleation Mechanism of MWCNTs for a Compound Catalyst
}

\author{
S. Shukrullah, ${ }^{1}$ N. M. Mohamed, ${ }^{2}$ Y. Khan, ${ }^{3}$ M. Y. Naz, ${ }^{1}$ A. Ghaffar, ${ }^{1}$ and I. Ahmad ${ }^{3}$ \\ ${ }^{1}$ Department of Physics, University of Agriculture, Faisalabad 38040, Pakistan \\ ${ }^{2}$ Center of Innovative Nanostructures and Nanodevices, Universiti Teknologi PETRONAS, Bandar Seri Iskandar, \\ 31750 Tronoh, Perak, Malaysia \\ ${ }^{3}$ Department of Electrical Engineering, King Saud University, Riyadh, Saudi Arabia
}

Correspondence should be addressed to S. Shukrullah; zshukrullah@gmail.com

Received 12 July 2017; Revised 21 October 2017; Accepted 29 October 2017; Published 14 November 2017

Academic Editor: Andrew R. Barron

Copyright (c) 2017 S. Shukrullah et al. This is an open access article distributed under the Creative Commons Attribution License, which permits unrestricted use, distribution, and reproduction in any medium, provided the original work is properly cited.

Activation of the catalyst particles during a CVD process can be anticipated from the carbon feeding rate. In this study, $\mathrm{Fe}_{2} \mathrm{O}_{3} / \mathrm{Al}_{2} \mathrm{O}_{3}$ catalyst was synthesized with uniformly dispersed iron over alumina support for onward production of multiwalled carbon nanotubes (MWCNTs) in a fluidized bed chemical CVD reactor. The effect of the ethylene flowrate on catalytic activity of the compound catalyst and morphology of the as-grown MWCNTs was also investigated in this study. The dispersed active phases of the catalyst and optimized gas flowrate helped in improving the tube morphology and prevented the aggregation of the as-grown MWCNTs. The flowrates, below $100 \mathrm{sccm}$, did not provide sufficient reactants to interact with the catalyst for production of defectfree CNT structures. Above $100 \mathrm{sccm}$, concentration of the carbon precursor did not show notable influence on decomposition rate of the gas molecules. The most promising results on growth and structural properties of MWCNTs were gained at ethylene flowrate of $100 \mathrm{sccm}$. At this flowrate, the ratio of $G$ and $D$ intensity peaks $\left(I_{G} / I_{D}\right)$ was deliberated about 1.40 , which indicates the growth of graphitic structures of MWCNTs.

\section{Introduction}

After their discovery by Iijima [1], carbon nanotubes (CNTs) continued to draw the tremendous attention of the research community due to their unique applications and properties. In nanotechnology, CNTs have been identified as one of the best materials for production of an array of industrial products [2]. Over the years, the researchers working in the field of nanotechnology have tried to synthesize CNTs through various techniques, such as arc discharge, laser excitation and ablation, chemical vapor deposition (CVD), and plasma assisted chemical vapor deposition (PECVD). However, CVD remains only the technique with scale-up potential for industrial scale delivery of nanotubes without compromising their selectivity, growth rate, yield, quality, and production cost [3].

Being an advanced form of CVD technique, fluidized bed chemical vapor deposition (FBCVD) involves the simultaneous decomposition of the carbon precursor over a pure metal or compound catalyst for nucleation of the nanotubes.
Having very simple production mechanism, FBCVD seems to be the most capable technique for bulk growth of CNTs with low process cost. The mechanism of production of CNTs in a FBCVD reactor is based on decomposition of the feedstock gas, dissolution of the carbon atoms in the catalyst particles, and precipitation of the carbon into nanotubes. The CNT production rate in a FBCVD reactor is controlled by the process temperature, variable parameters of the metal catalyst, precursor flowrate, and deliberately chosen carrier gas. Similarly, the structural quality and yield of the carbon product can be improved by deliberating the process parameters, such as carbon precursor, process temperature, composition of the catalyst, catalyst preparation technique, size of the catalyst particles, and the catalyst support [4]. However, FBCVD growth of CNTs is still a complex phenomenon, especially in the context of catalyst activity and tube nucleation mechanism. Therefore, a detained knowledge on growth route of nanotubes and the role of the catalyst during carbon precipitation is yet to arrive at. 
Tee et al. [5] conducted research investigations on the role of process temperature and gas flowrate for production of MWCNTs with a CVD technique. They decomposed acetylene with a metal catalyst at different temperatures in the range of $700-850^{\circ} \mathrm{C}$. The acetylene flowrate was also varied from 15 to $30 \mathrm{sccm}$ to study the effect of feeding rate on the product yield. The carbon yield revealed a concomitant increase over process temperature and gas feeding rate. Zhan et al. [6] revealed that excessive gas feeding may increase the resident time of the carbon source on the surface of the catalyst particles. As a result, a large number of gas molecules would decompose for carbon buildup into smooth CNT structures at faster rates. The high gas flowrate promotes the gas-catalyst interaction and decomposition of the molecules at the catalyst surface and consequently the growth rate of CNT structures. Tripathi et al. [7] worked on CVD process time and gas flowrate for optimization of structural properties of the nanotubes. They noticed an inverse relationship between the tube length and the gas feeding rate. However, unlike others, Hernadi et al. [8] and Qian et al. [9] reported insignificant impact of gas feeding rate on structural morphology of the nanotubes.

The diameter of the nanotubes can be governed by controlling the activation of the catalyst particles to an optimized gas feeding rate $[9,10]$. At unoptimized flowrates, the large catalyst particles remain underfed and do not assist the growth of nanotubes. Contrarily, the small catalyst particles remain cutoff from the carbon feed after deposition of one or more graphene layers on them. Therefore, moderate particle sizes should be chosen for improved nucleation of nanotubes. Most part of the past literature, dealing with production of CNTs via FBCVD technique, was focused on the influence of the temperature, catalyst type, carbon precursor, and gas pressure on the surface and structural morphology of the asgrown CNTs. The role of the gas flowrate on the morphology, structure, quality, and quantity of the nanotubes was not acknowledged appropriately. In this study, the effect of the flowrate on growth mechanism and structural properties of MWCNTs, grown with $\mathrm{Fe}_{2} \mathrm{O}_{3} / \mathrm{Al}_{2} \mathrm{O}_{3}$ compound catalyst, is addressed by varying the ethylene flowrate from 50 to $150 \mathrm{sccm}$ and by keeping the process time and temperature fixed at $60 \mathrm{~min}$ and $800^{\circ} \mathrm{C}$, respectively. $\mathrm{Fe}_{2} \mathrm{O}_{3} / \mathrm{Al}_{2} \mathrm{O}_{3}$ catalyst was used to grow MWCNTs in a FBCVD reactor. The effect of the ethylene flowrate on catalytic activity of the compound catalyst and morphology of as-grown MWCNTs was examined using FESEM, TEM, Raman spectroscopy, and elemental mapping techniques. The findings of the presented work are discussed in subsequent sections.

\section{Methodology}

2.1. Synthesis of Compound Catalyst. To catalyze the CVD growth of MWCNTs, a compound catalyst, namely, $\mathrm{Fe}_{2} \mathrm{O}_{3} / \mathrm{Al}_{2} \mathrm{O}_{3}$, was synthesized through coprecipitation of ferric nitrate " $\mathrm{Fe}\left(\mathrm{NO}_{3}\right)_{3} \cdot 9 \mathrm{H}_{2} \mathrm{O}$ " and aluminum nitrate " $\mathrm{Al}\left(\mathrm{NO}_{3}\right)_{3} \cdot 9 \mathrm{H}_{2} \mathrm{O}$." The chemicals, used in preparation of the metal catalyst, were supplied by SIGMA-ALDRICH. Chemicals were of analytical grade and used without further purification. Ferric nitrate and aluminum nitrate were dissolved in ethanol to obtain $\mathrm{Fe}_{2} \mathrm{O}_{3}$ and $\mathrm{Al}_{2} \mathrm{O}_{3}$ and from there $\mathrm{Fe}_{2} \mathrm{O}_{3} / \mathrm{Al}_{2} \mathrm{O}_{3}$ catalyst was synthesized. Ferric nitrate and aluminum nitrate were used as precursors of $\mathrm{Fe}_{2} \mathrm{O}_{3}$ and $\mathrm{Al}_{2} \mathrm{O}_{3} .8 \mathrm{~g}$ of ferric nitrate and $10 \mathrm{~g}$ of aluminum nitrate were dissolved separately in $100 \mathrm{ml}$ and $200 \mathrm{ml}$ of ethanol, respectively. Both solutions were subjected to magnetic stirring and thereafter mixed together. Roughly, $200 \mathrm{ml}$ of ammonium hydroxide was also added to the mixture with continuous stirring. In this case, the ammonium hydroxide acted as a precipitant. The final product was filtered, washed, and dried in an oven at $110^{\circ} \mathrm{C}$ for 6 hours. The fully dried catalyst was grinded and sieved to obtain the particle size of 60 microns. After grinding, the catalyst was calcined at $300^{\circ} \mathrm{C}$ for 5 hours and stored in a vacuum tight glass jar.

2.2. Synthesis of MWCNTs. This compound catalyst powder was used to decomposed ethylene gas for production of MWCNTs in a FBCVD reactor [4]. The experimental setup, considered for growth of CNT structures, is shown schematically in Figure 1. The shown FBCVD reactor was having a quartz tube passing through the furnace heating zone. A digital controller, governing the furnace temperature, was used to fix the CVD temperature. The ethylene flowrate was monitored with a gas flowmeter. Figure 2 reports the heating profile of FBCVD growth process observed during the synthesis process. First of all, CVD process temperature was optimized for structural growth of MWCNTs. The CVD reactor was operated at different process temperatures, ranging from $600^{\circ} \mathrm{C}$ to $1000^{\circ} \mathrm{C}$, by fixing the process time at $60 \mathrm{~min}$. Once the optimum temperature was identified, the catalyst weight and process time were varied for their optimization and identification of the best process conditions for the growth of well-structured MWCNTs.

Firstly, $1 \mathrm{~g}$ of the compound catalyst was taken on grit. The grit was placed on a holder fixed at the bottom of the quartz tube, just above the gas distributor. The process temperature was raised to the optimum value of $800^{\circ} \mathrm{C}$ with concurrent supply of argon gas. At this point, hydrogen and ethylene gases were also introduced into the quartz tube. All the gases at their suggested flowrates were mixed in a mixture coupled with the lower part of the quartz tube. The gas flowrate from the supply point to the mixer was regulated using digital flowmeters. Initially, the flowrate of argon, hydrogen, and ethylene gases was fixed to $250 \mathrm{sccm}, 50 \mathrm{sccm}$, and $50 \mathrm{sccm}$, respectively. After $60 \mathrm{~min}$ of growth time, hydrogen and ethylene supply was stopped. The carbon product was set to cool overnight at room temperature with continuous supply of argon gas at $250 \mathrm{sccm}$. Same step was repeated to obtain nanotubes at ethylene flowrates of $50,75,100,125$, and $150 \mathrm{sccm}$.

The final product was characterized by using a set of characterization techniques. FESEM was used to study the surface morphology, elemental mapping at microstructural level, tube length, thickness, and outer diameter of the asgrown CNTs. High resolution TEM technique was used to elaborate the surface defects, internal structures, wall number, innerlayer spacing, and microstructures of the asgrown CNTs. The nanotubes were sonicated before performing TEM analysis by dispersing them in isopropanol for 


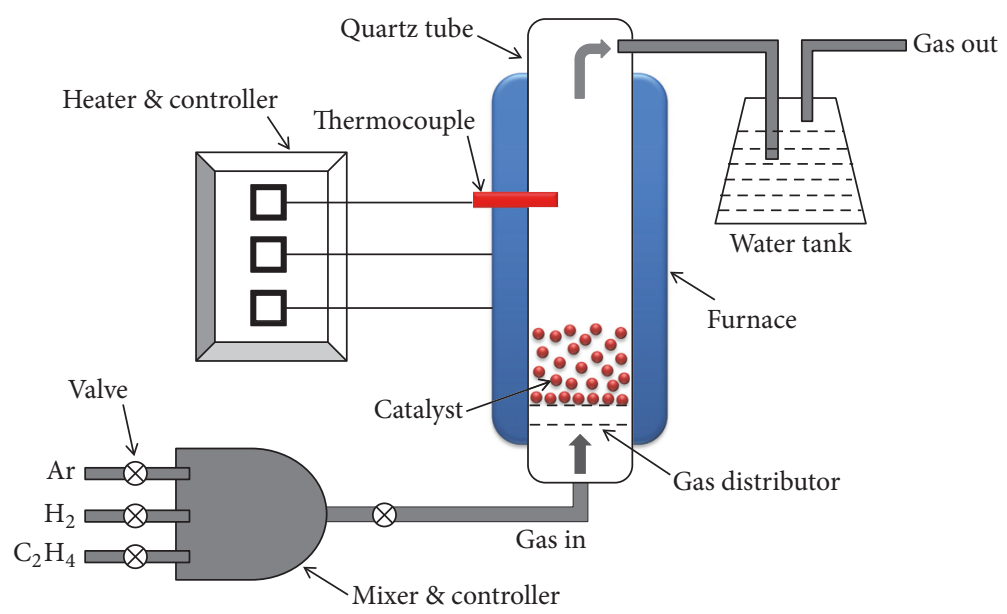

FIGURE 1: Schematic of the FBCVD setup for production of MWCNTs.

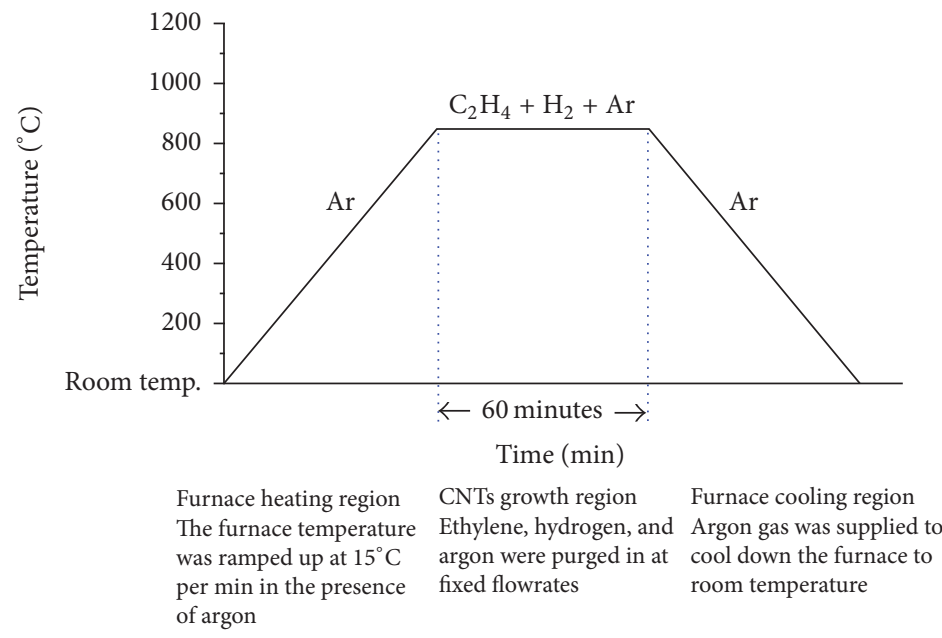

FIgURE 2: A typical temperature profile of FBCVD process.

$15 \mathrm{~min}$. Thereafter, TEM images of the sonicated MWCNTs were produced at different resolutions. To avoid the tube damaging, TEM setup was operated at voltages below $86 \mathrm{keV}$. About 50 tubes in TEM image of each sample were chosen to provide meaningful comparison of the average tube diameter of the tested samples. In line with this, Raman spectra of the samples were also generated to investigate the crystallinity and purity of the as-grown nanotubes. The ratios of different intensity bands in Raman spectra were used as an indicator of tube crystallinity.

\section{Results and Discussion}

SEM based element mapping is very useful technique to display the distribution of the elements in textural context and particularly to show the compositional zonation. The EDX generated elemental maps provide the spatial distribution of the elements in the compound catalyst sample. Elemental mapping at the microstructural level, carried out using FESEM based EDX, was used to find the catalyst composition and dispersion of the iron on alumina support.
The mapping images of the tested catalyst are shown in Figure 3. These images revealed the presence of $\mathrm{O}, \mathrm{Al}$, and $\mathrm{Fe}$ elements in the catalyst. The mapping profiles also reflect that the iron species were uniformly dispersed on the surface of alumina.

EDX spectrum of the compound catalyst was also taken to verify the presence of $\mathrm{O}, \mathrm{Al}$, and $\mathrm{Fe}$ in the catalyst and to find their relative wt.\% in the formulation. Figure 4 shows the EDX profile confirming the existence of $\mathrm{O}, \mathrm{Al}$, and Fe elements in the formulation. The relative wt.\% of the elements, identified in the EDX spectrum, are given in Table 1. The wt.\% of $\mathrm{O}, \mathrm{Al}$, and $\mathrm{Fe}$ was measured about $44.49 \%$, $21.70 \%$, and $33.81 \%$, respectively. The uniformly dispersed iron with high concentration, as observed in EDX analysis and elemental mapping, was supportive of high growth rate of CNTs. Lu et al. [10, 11] tested two compositions of $\mathrm{Fe}_{2} \mathrm{O}_{3} / \mathrm{Al}_{2} \mathrm{O}_{3}$ catalyst for production of CNTs. It was reported that both compositions are equivalent with respect to the rate of decomposition of the carbon precursor. However, high yield of CNTs was obtained with the catalyst having high concentration of $\mathrm{Fe}_{2} \mathrm{O}_{3}$. In line with this, Abad et al. [12] 

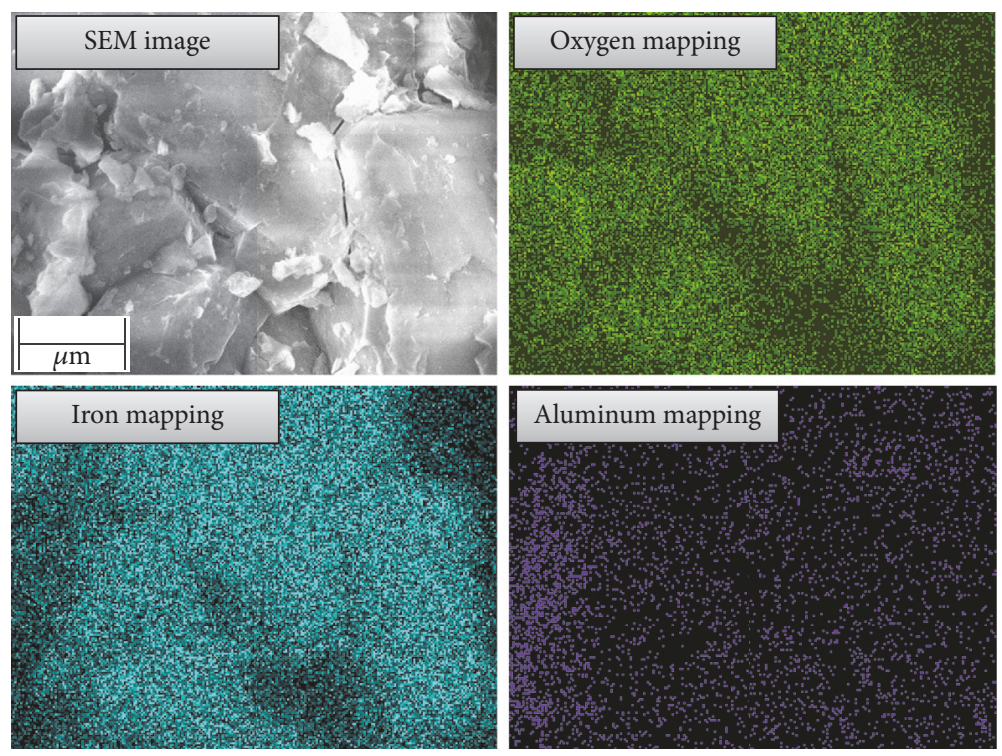

FIGURE 3: Elemental mapping of the compound catalyst.

TABLE 1: EDX based elemental analysis of the compound catalyst.

\begin{tabular}{lcc}
\hline Element & Weight\% & Atomic\% \\
\hline Oxygen & 33.81 & 54.76 \\
Aluminum & 21.70 & 18.30 \\
Iron & 44.49 & 26.94 \\
\hline Total & 100 & 100 \\
\hline
\end{tabular}

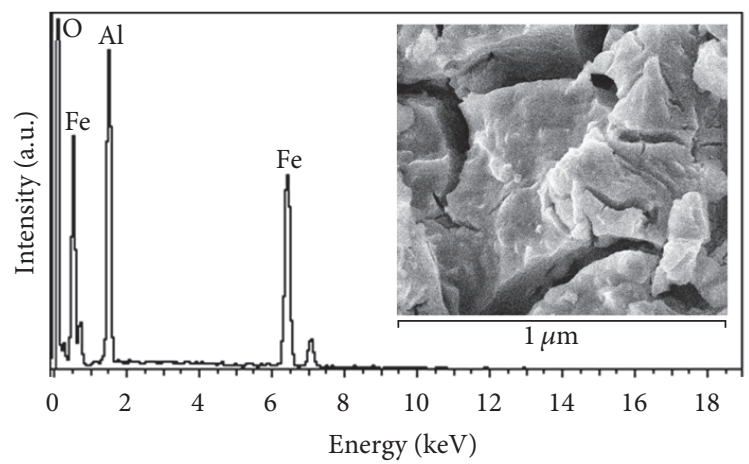

FIGURE 4: EDX spectrum of the compound catalyst.

and Kierzkowska et al. [13] showed that $\mathrm{Fe}_{2} \mathrm{O}_{3} / \mathrm{Al}_{2} \mathrm{O}_{3}$ catalyst with high wt.\% of $\mathrm{Fe}_{2} \mathrm{O}_{3}$ produces better results on catalytic activity and decomposition rate and consequently the carbon product yield.

Alumina is reported as a better catalyst support than the other materials, allowing high density of the active catalytic sites and metal dispersion [13]. The chemical interactions between $\mathrm{Al}_{2} \mathrm{O}_{3}$ support and the metal catalyst expedite the oxidation at the catalyst- $\mathrm{Al}_{2} \mathrm{O}_{3}$ interfaces. The $\mathrm{Al}_{2} \mathrm{O}_{3}$ support also prevents the sintering of the catalyst particles, disperses the active phases of the catalyst, and improves the mechanical properties. Such morphology of the catalyst prevents the

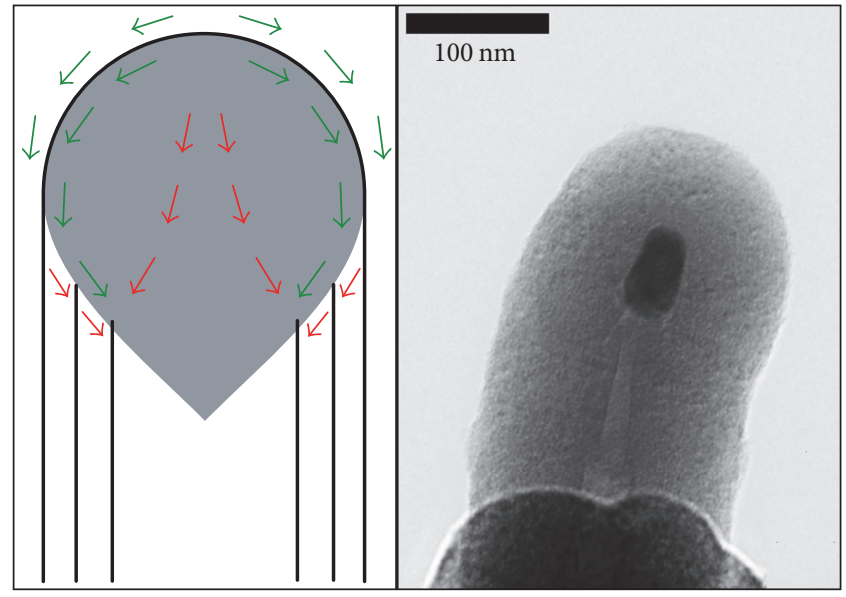

FIGURE 5: Carbon diffusion in outer and subsurface of catalyst particles for nucleation of MWCNTs.

aggregation of the metal species and formation of unwanted large clusters, which may result in growth of CNTs with many structural defects [14].

Figure 5 shows the possible route for carbon diffusion in outer and subsurfaces of the catalyst particles during CVD growth of MWCNTs. The possible and forbidden paths for carbon diffusion on catalyst are marked with green and red arrows, respectively. The growth of the outer-most tube wall occurred through surface diffusion of the carbon atoms. However, as the outer-most tube grows via tip growth and attaches to the catalyst particle, the growth of the inner tubes may not be occurring solely due to surface diffusion. Although bulk diffusion has been denied for excessive growth of MWCNTs, the subsurface diffusion of some of the carbon atoms might be happening during the development of internal walls of a MWCNT. 


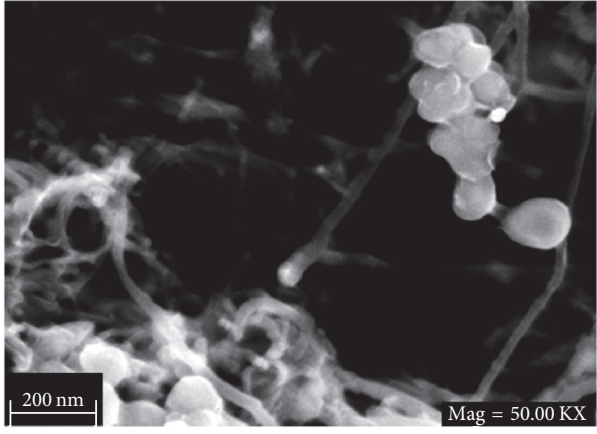

(a) $50 \mathrm{sccm}$

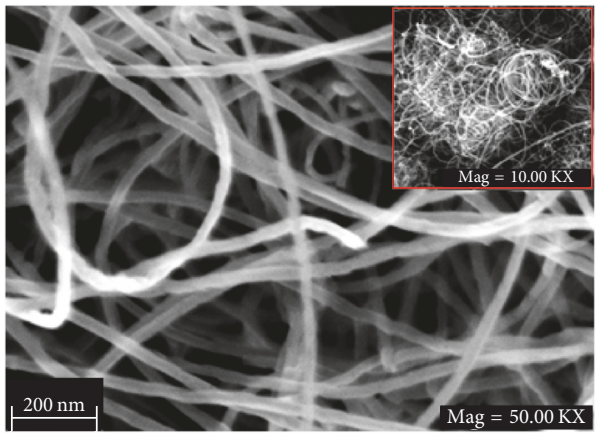

(c) $100 \mathrm{sccm}$

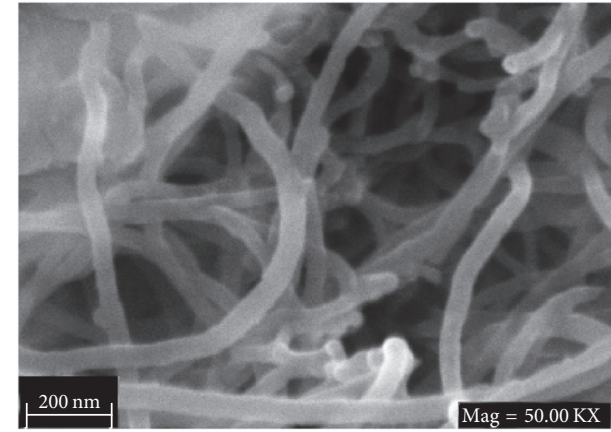

(b) $75 \mathrm{sccm}$

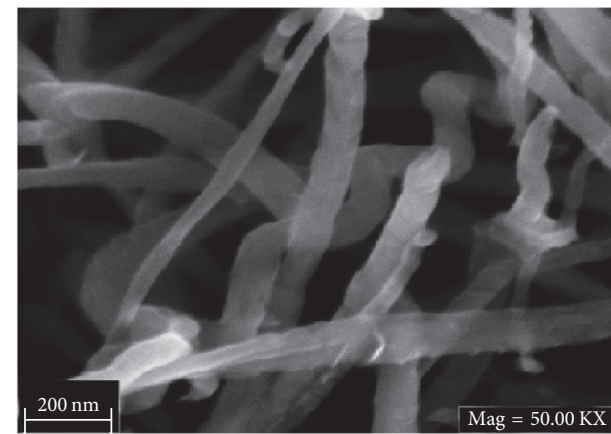

(d) $125 \mathrm{sccm}$

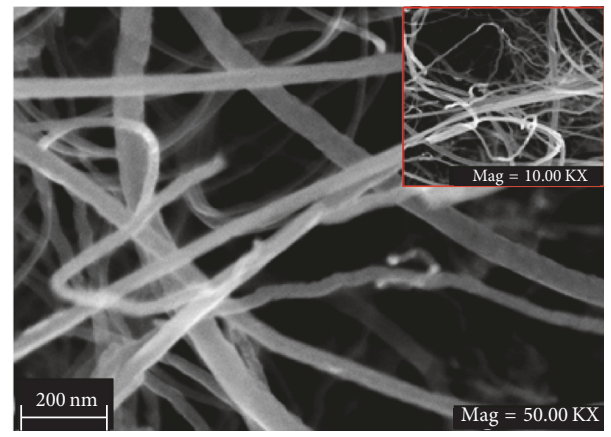

(e) $150 \mathrm{sccm}$

FIGURE 6: Selected FESEM micrographs of MWCNTs grown with different ethylene flowrates.

The structural growth and surface morphology of the asgrown MWCNTs were determined from SEM micrographs obtained at different magnifications. Figure 6 shows SEM micrographs of MWCNTs produced with ethylene flowrates of $50,75,100,125$, and $150 \mathrm{sccm}$. For a flowrate of $50 \mathrm{sccm}$, hardly very few CNTs were formed; majority of the carbon product was formed of unwanted debris of amorphous carbon and inactivate or poisoned catalyst, as shown in Figure 6(a). It reflects that the ethylene flowrate was not enough to initiate the fast growth of CNTs on thermally activated catalyst. The catalyst reacted inadequately with the carbon precursor due to least availability of the carbon atoms to diffuse into the metal catalyst.

At an ethylene flowrate of $75 \mathrm{sccm}$, although product yield exhibited a slight increase, most of the nanotubes were found defective and broken by showing large number of defects in the grown CNT structures. These structural defects reflect that the gas feeding at $75 \mathrm{sccm}$ was not enough to fully fluidize the catalytic particles and to produce sufficient carbon atoms to diffuse and grow into continuous CNT structures. However, as the ethylene flowrate was raised further to $100 \mathrm{sccm}$, relatively longer nanotubes with outer tube diameter in the range of 20 to $25 \mathrm{~nm}$ were seen in the SEM micrographs (Figure 6(c)). This flowrate provided a sufficient push to the catalyst particles to suspend in the bed column and to make good contact with the gas molecules. The improved catalytic activity of the catalyst and the balanced dissociation of the carbon precursor resulted in the formation of MWCNT structures of high crystallinity. The \% yield of the as-grown nanotubes was also increased at the optimized flowrate.

These investigations revealed notable effect of the ethylene flowrate on morphology and structural properties of the nanotubes. SEM micrograph in Figure 6(c) reflects improved 


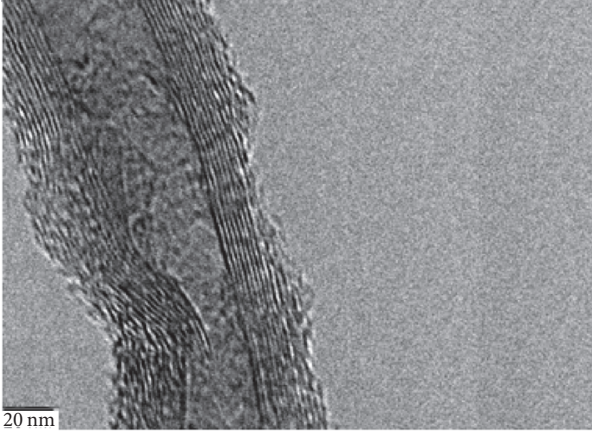

(a) $50 \mathrm{sccm}$

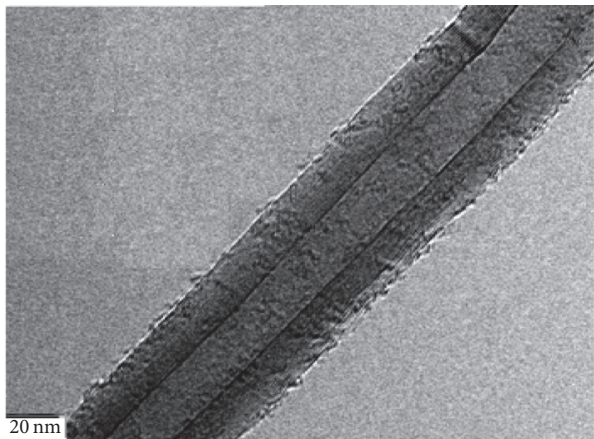

(c) $100 \mathrm{sccm}$

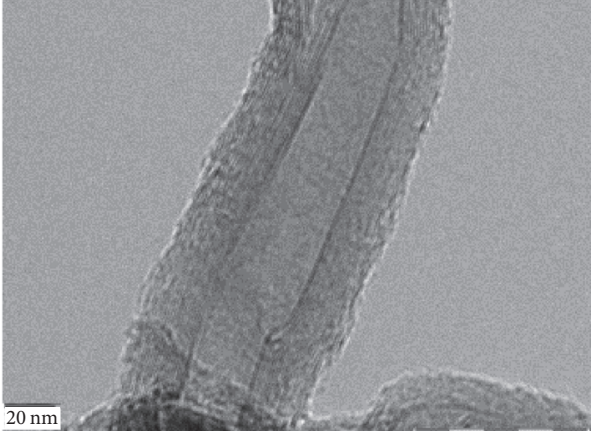

(b) $75 \mathrm{sccm}$

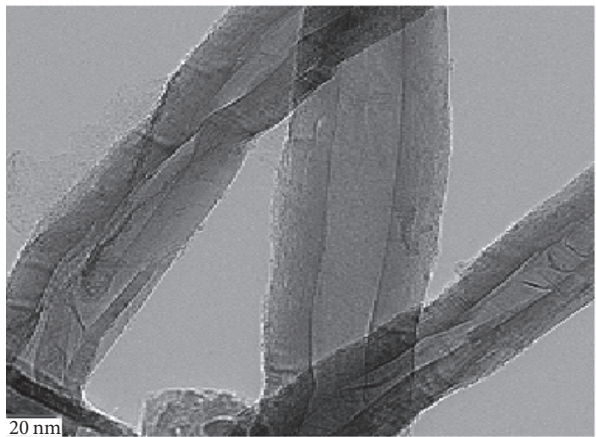

(d) $125 \mathrm{sccm}$

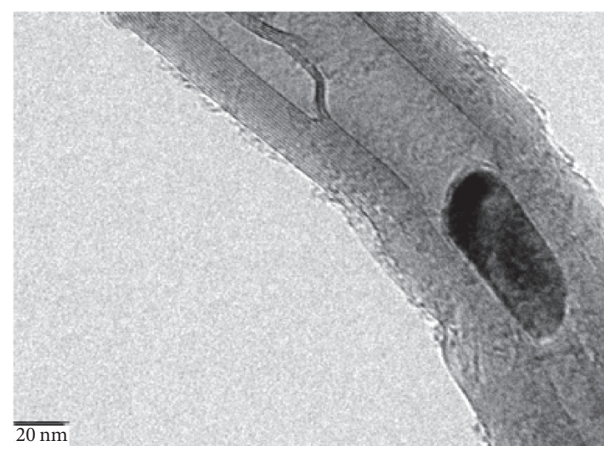

(e) $150 \mathrm{sccm}$

FIGURE 7: TEM micrographs of MWCNTs grown at different ethylene flowrates.

growth and structural parameters at flowrate of $100 \mathrm{sccm}$. No traces of unused catalyst and amorphous carbon were realized in the SEM micrographs of CNTs produced with this flowrate. However, a further increase in flowrate above $100 \mathrm{sccm}$ brought some degradation in the CNT structures. At 125 and $150 \mathrm{sccm}$, a notable proportion of the product exhibited structural defects and the lumps of the amorphous carbon were also spotted in SEM micrographs. These structural defects are attributed to the large number of the molecules undergoing catalytic decomposition. At such flowrates, the rate of decomposition of ethylene might have exceeded the rate of carbon diffusion. The outer diameter was widely distributed in the range of $18 \mathrm{~nm}$ to $59 \mathrm{~nm}$ at $150 \mathrm{sccm}$, as shown in Figure 6(e). Conclusively, $100 \mathrm{sccm}$ was regarded as an optimum flowrate for production of MWCNTs with a $\mathrm{Fe}_{2} \mathrm{O}_{3} / \mathrm{Al}_{2} \mathrm{O}_{3}$ compound catalyst in $\mathrm{FBCVD}$ reactor. At optimized flowrate, most of the catalyst was get utilized and there was no amorphous carbon and deactivated catalyst left in the final product.

Generally, CNTs growth in a CVD reactor depends on dissociation of gas molecules into carbon atoms, which diffuse into catalyst particles and then precipitate out in the form of nanotubes. The growth of tubular structures of better quality strongly depends on the type and flowrate of the carbon precursor $[12,15-18]$. In this study, the crystallinity of CNT structures was elaborated from the TEM micrographs obtained with different spatial resolutions. MWCNTs were dispersed in isopropanol for $15 \mathrm{~min}$ to minimize the agglomeration and loaded on a TEM grid to obtain the micrographs. The TEM micrographs, as shown in Figure 7, confirmed the formation of only MWCNTs. Very few nanotubes were formed at flowrates below $100 \mathrm{sccm}$. The 


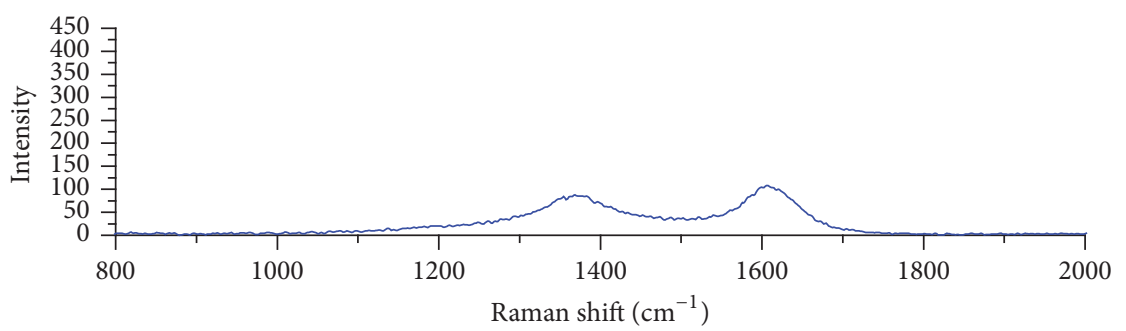

(a) $50 \mathrm{sccm}$

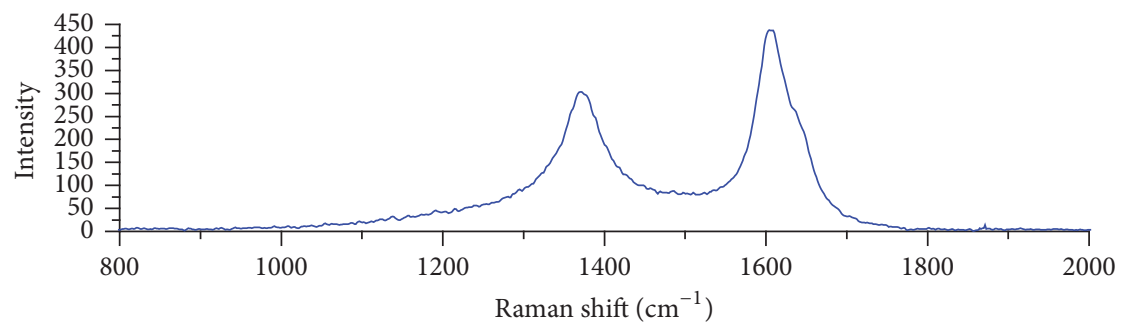

(b) $100 \mathrm{sccm}$

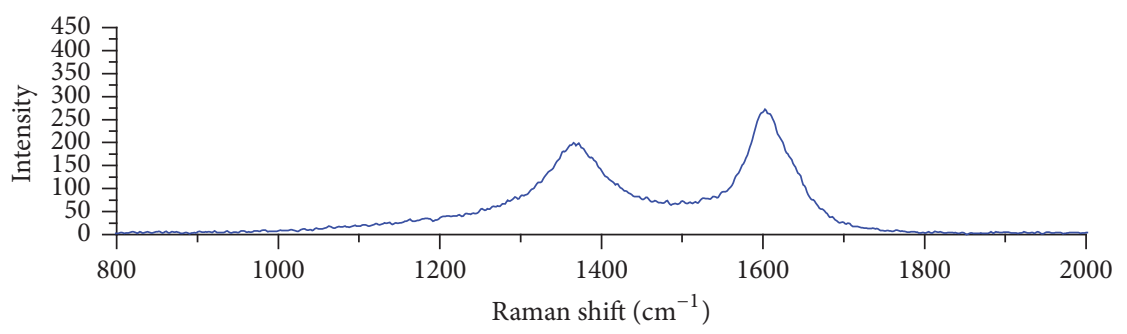

(c) $150 \mathrm{sccm}$

FIGURE 8: Raman spectra of MWCNTs grown with different ethylene flowrates.

inadequate decomposition of the molecules into hydrogen and carbon happened due to low flowrate of the precursor gas. At gas flowrates of 50 and $75 \mathrm{sccm}$, the low yield of CNTs is ascribed to deactivation of the atoms of the metal catalyst, as shown in Figure 7(a). The ethylene flowrate was not enough to fully fluidize the catalytic particles and to produce sufficient carbon atoms to diffuse and grow into continuous CNT structures. Agglomeration of the unreacted catalyst can clearly be seen in SEM and TEM micrographs at flowrates less than $100 \mathrm{sccm}$. The carbon deficiency resulted in defective nanotubes, which were broken and bent in an irregular manner [18-21].

The diameter of the nanotubes can be controlled by optimizing the gas feeding rate. At unoptimized flowrates, the large catalyst particles remain underfed and do not assist the growth of nanotubes. Contrarily, the small catalyst particles remain cutoff from the carbon feed after deposition of one or more graphene layers. At $100 \mathrm{sccm}$, uniform networks of CNT structures having narrow diameter distribution (20 to $25 \mathrm{~nm}$ ) were evident, as shown in Figure 7(c). It shows that the rate of formation and removal of the carbon atoms from the surface of the catalyst exactly matches at this flowrate and yields equilibrium among the supply of the reactive carbon and nucleation of CNT structures $[6,8]$. With further increase in ethylene flowrate from $100 \mathrm{sccm}$, some of the structures were found defective. These tube structures were broken and bent from different places. Some catalyst particles were also found trapped in the tube structures, which result in defective structures with random tube growth rather than the freestanding tube growth. At high process temperature of $800^{\circ} \mathrm{C}$, the catalyst powder is anticipated to melt and deform; therefore the catalyst particles were deeply rooted into the tube structures, as illustrated in Figure $7(\mathrm{e})$. At higher flowrates, the structural defects are attributed to the large number of the molecules undergoing catalytic decomposition and the rate of decomposition of ethylene might have exceeded the rate of carbon diffusion. Therefore, the outer diameter was also widely distributed, as shown in Figure 7(e).

Raman spectroscopy is also a useful tool to study the crystallinity the nanotubes [19]. The Raman spectra of the samples, produced with different ethylene flowrates, are shown in Figure 8. The Raman shift in the range of $1360-1375 \mathrm{~cm}^{-1}$ refers to $D$ intensity band (disordered structure) whereas the Raman shift in the range of $1600-1610 \mathrm{~cm}^{-1}$ corresponds to $G$ band (graphitic structure). In this study, there were two major peaks in Raman spectrum of each sample, regardless of the ethylene flowrate. A prominent $G$ band in the spectrum at $100 \mathrm{sccm}$ reflected the growth of symmetric structures of MWCNTs and $D$ band revealed the formation of defective layers in the structures. Therefore, the peak intensity ratio $\left(I_{G} / I_{D}\right)$ was calculated to assess the structure quality from 
the relative response of the well-graphitized carbon to the defective carbon. In this study, $I_{G} / I_{D}$ ration was found 1.22 , 1.40 , and 1.38 for flowrates of $50 \mathrm{sccm}, 100 \mathrm{sccm}$, and $150 \mathrm{sccm}$, respectively, which indicates that as-grown MWCNTs had good graphitic structures at optimized flowrate of $100 \mathrm{sccm}$.

\section{Conclusions}

In this detailed note, the effect of the ethylene flowrate of on the structural morphology and quality of MWCNTs was investigated using a fluidized bed CVD reactor. The effect of the ethylene flowrate on structural properties and yield of MWCNTs was quantified using SEM, elemental mapping, TEM, and Raman spectroscopy techniques. From these analyses, it was concluded that the growth of relatively pure, dense, and homogeneous MWCNTs is possible with optimized ethylene flowrate of $100 \mathrm{sccm}$. At an optimum flowrate condition, the growth of relatively longer tubes with controlled diameter distribution $(20-25 \mathrm{~nm})$ was noticed in TEM micrographs. At $150 \mathrm{sccm}$, trapping of the catalyst particles by the CNT structures and growth of nanotubes with wide diameter distribution were predicted. In a fully optimized FBCVD growth process, an equilibrium condition appears between the rate of decomposition of ethylene and the rate of diffusion of carbon into the catalyst particles. Below 100 sccm of ethylene, the CVD process could not make full use of the catalyst particles. The smaller numbers of reactive carbon atoms resulted in growth of fewer nanotubes with higher structural defects. Conclusively, the precursor flowrate may notably influence the quantity, crystallinity, diameter distribution, and other structural properties of the nanotubes.

\section{Conflicts of Interest}

The authors declare that there are no conflicts of interest regarding the publication of this paper.

\section{Acknowledgments}

The authors would like to extend their sincere appreciation to the Deanship of Scientific Research at King Saud University for funding this work through Research Group no. RG1438012 .

\section{References}

[1] S. Iijima, "Helical microtubules of graphitic carbon," Nature, vol. 354, no. 6348, pp. 56-58, 1991.

[2] J. Mauricio Rosolen, C. H. Patrick Poá, S. Tronto, M. S. Marchesin, and S. R. P. Silva, "Electron field emission of carbon nanotubes on carbon felt," Chemical Physics Letters, vol. 424, no. 1-3, pp. 151-155, 2006.

[3] S. Shukrullah, N. M. Mohamed, M. S. Shaharun, and M. Y. $\mathrm{Naz}$, "Mass production of carbon nanotubes using fluidized bed reactor: a short review," Trends in Applied Sciences Research, vol. 9, no. 3, pp. 121-131, 2014.

[4] S. Shukrullah, N. M. Mohamed, M. S. Shaharun, and M. Y. Naz, "Effect of ferrocene concentration on the quality of multiwalled
CNTs grown by floating catalytic chemical vapor deposition technique," Main Group Chemistry, vol. 13, no. 3, pp. 251-259, 2014.

[5] J. C. Tee, M. Aziz, A. F. Ismail, M. Rusop, and T. Soga, "Effect of Reaction Temperature and Flow Rate of Precursor on Formation of Multi-Walled Carbon Nanotubes," in Proceedings of the Nanoscience and Nanotechnology: International Conference on Nanoscience and Nanotechnology, pp. 214-218, Shah Alam, Selandor (Malaysia), 2008.

[6] S. Zhan, Y. Tian, Y. Cui et al., "Effect of process conditions on the synthesis of carbon nanotubes by catalytic decomposition of methane," China Particuology, vol. 5, no. 3, pp. 213-219, 2007.

[7] N. Tripathi, P. Mishra, H. Harsh, and S. S. Islam, "Fine-tuning control on CNT diameter distribution, length and density using thermal CVD growth at atmospheric pressure: an in-depth analysis on the role of flow rate and flow duration of acetylene (C2H2) gas," Applied Nanoscience, vol. 5, no. 1, pp. 19-28, 2015.

[8] K. Hernadi, A. Fonseca, J. B. Nagy, A. Siska, and I. Kiricsi, "Production of nanotubes by the catalytic decomposition of different carbon-containing compounds," Applied Catalysis A: General, vol. 199, no. 2, pp. 245-255, 2000.

[9] W. Qian, H. Yu, F. Wei, Q. Zhang, and Z. Wang, "Synthesis of carbon nanotubes from liquefied petroleum gas containing sulfur [4]," Carbon, vol. 40, no. 15, pp. 2968-2970, 2002.

[10] C. Lu and J. Liu, "Controlling the diameter of carbon nanotubes in chemical vapor deposition method by carbon feeding," The Journal of Physical Chemistry B, vol. 110, no. 41, pp. 20254-20257, 2006.

[11] K. B. Kouravelou and S. V. Sotirchos, "Dynamic study of carbon nanotubes production by chemical vapor deposition of alcohols," Reviews on Advanced Materials Science, vol. 10, no. 3, pp. 243-248, 2005.

[12] A. Abad, F. García-Labiano, L. F. de Diego, P. Gayán, and J. Adánez, "Reduction kinetics of $\mathrm{Cu}-, \mathrm{Ni}$-, and $\mathrm{Fe}$-based oxygen carriers using syngas $(\mathrm{CO}+\mathrm{H} 2)$ for chemical-looping combustion," ENERGY \& FUELS, vol. 21, no. 4, pp. 1843-1853, 2007.

[13] A. M. Kierzkowska, C. D. Bohn, S. A. Scott, J. P. Cleeton, J. S. Dennis, and C. R. Müller, "Development of iron oxide carriers for chemical looping combustion using Sol-Gel," Industrial \& Engineering Chemistry Research, vol. 49, no. 11, pp. 5383-5391, 2010.

[14] N. Nagaraju, A. Fonseca, Z. Konya, and J. B. Nagy, "Alumina and silica supported metal catalysts for the production of carbon nanotubes," Journal of Molecular Catalysis A: Chemical, vol. 181, no. 1-2, pp. 57-62, 2002.

[15] H. Ago, K. Nakamura, N. Uehara, and M. Tsuji, "Roles of metal-support interaction in growth of single- and doublewalled carbon nanotubes studied with diameter-controlled iron particles supported on MgO," The Journal of Physical Chemistry $B$, vol. 108, no. 49, pp. 18908-18915, 2004.

[16] K. Dasgupta, J. B. Joshi, and S. Banerjee, "Fluidized bed synthesis of carbon nanotubes-a review," Chemical Engineering Journal, vol. 171, no. 3, pp. 841-869, 2011.

[17] K. J. MacKenzie, O. M. Dunens, and A. T. Harris, "An updated review of synthesis parameters and growth mechanisms for carbon nanotubes in fluidized beds," Industrial \& Engineering Chemistry Research, vol. 49, no. 11, pp. 5323-5338, 2010.

[18] H. Dai, "Carbon nanotubes: opportunities and challenges," Surface Science, vol. 500, no. 1-3, pp. 218-241, 2002.

[19] T.-C. Cheng, "Effect of nitrogen and hydrogen on the growth of multiwall carbon nanotubes on flexible carbon cloth using 
thermal chemical vapor deposition," Materials Chemistry and Physics, vol. 136, no. 1, pp. 140-145, 2012.

[20] Q. Li, H. Yan, J. Zhang, and Z. Liu, "Effect of hydrocarbons precursors on the formation of carbon nanotubes in chemical vapor deposition," Carbon, vol. 42, no. 4, pp. 829-835, 2004.

[21] S. Shukrullah, N. M. Mohamed, and M. S. Shaharun, "Optimum temperature on structural growth of multiwalled carbon nanotubes with low activation energy," Diamond and Related Materials, vol. 58, article no. 6428, pp. 129-138, 2015. 

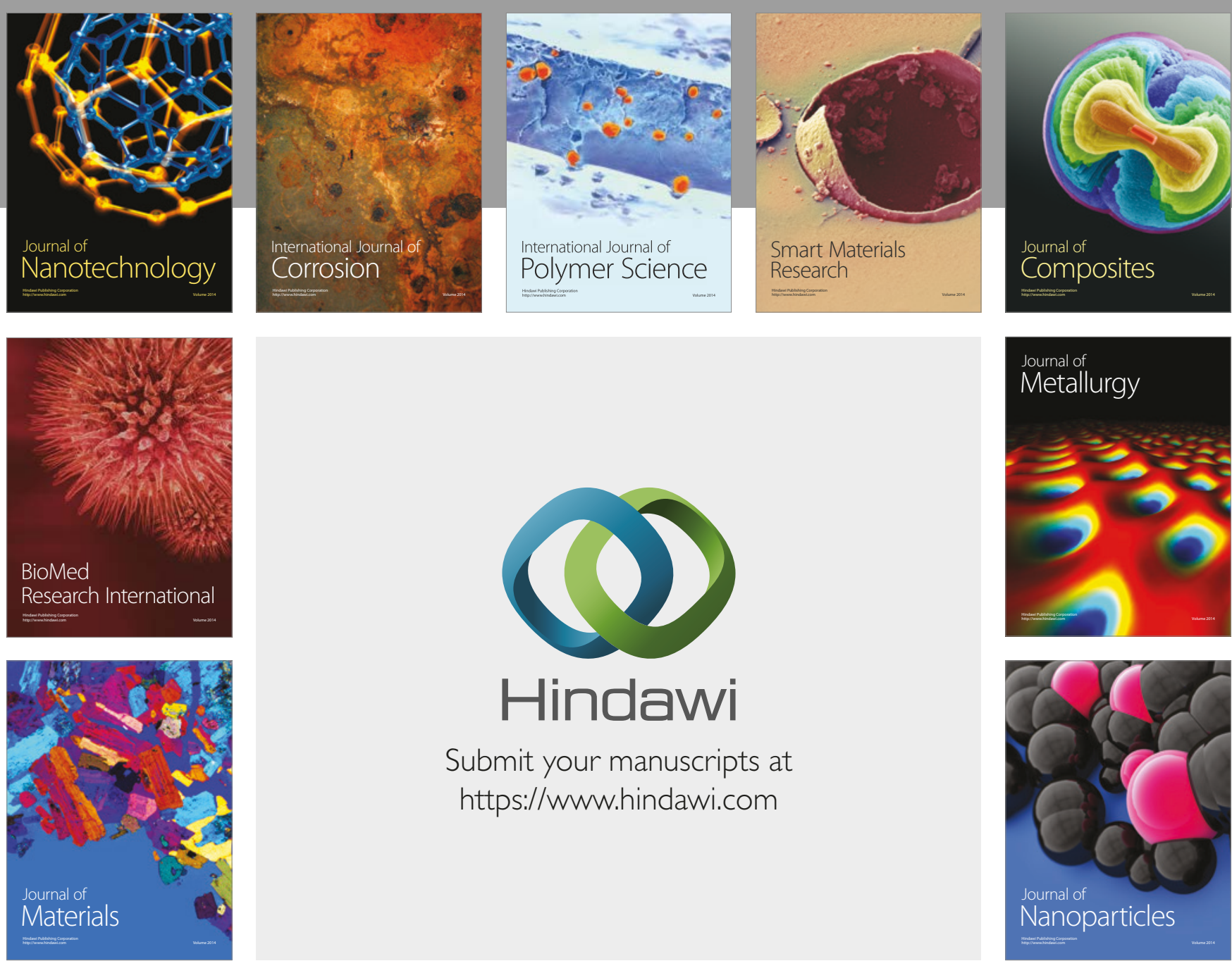

\section{Hindawi}

Submit your manuscripts at

https://www.hindawi.com
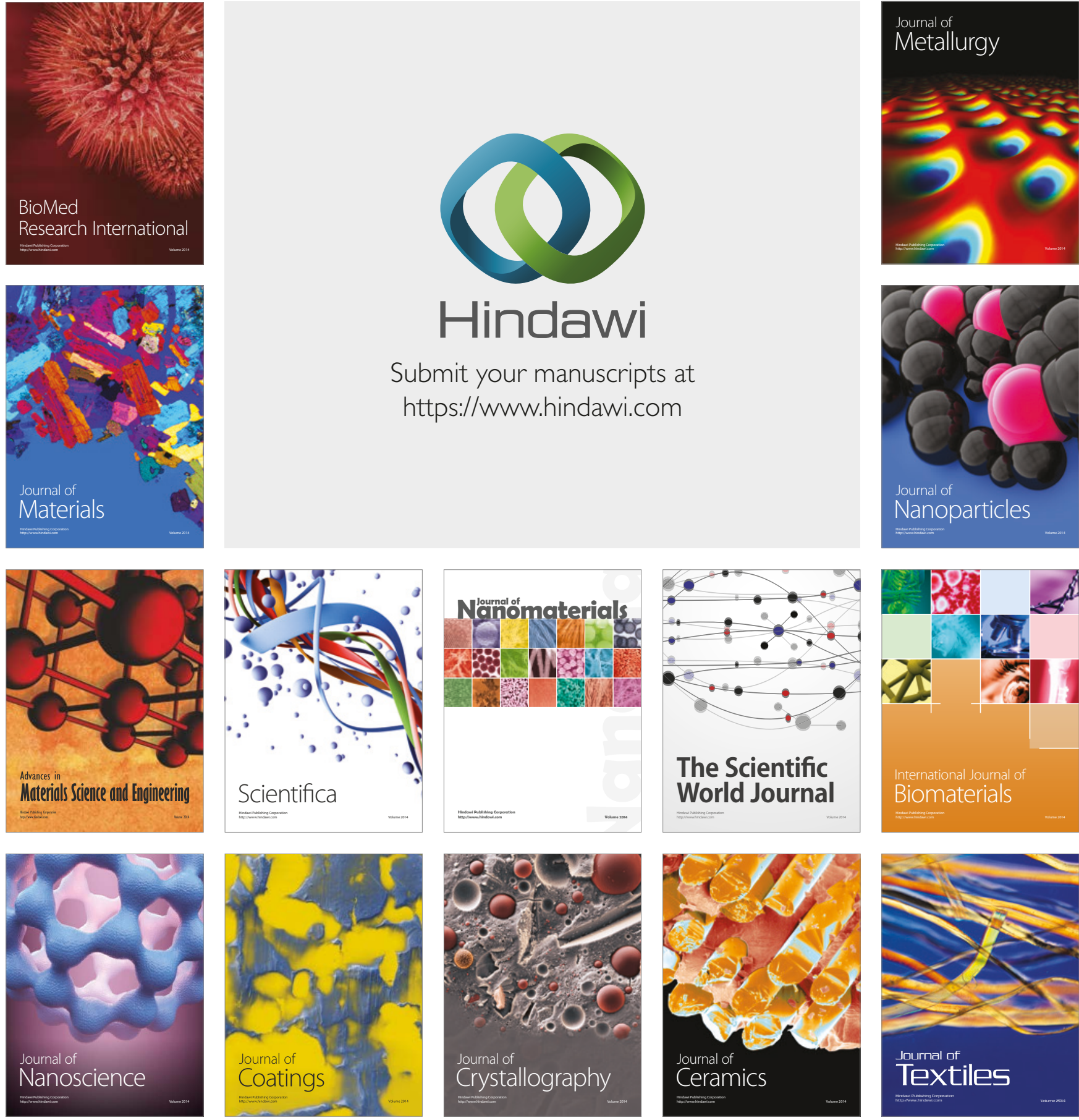

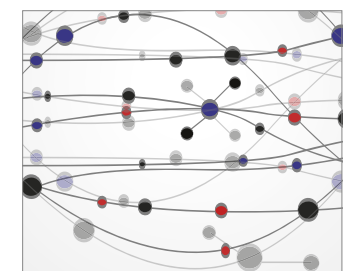

The Scientific World Journal
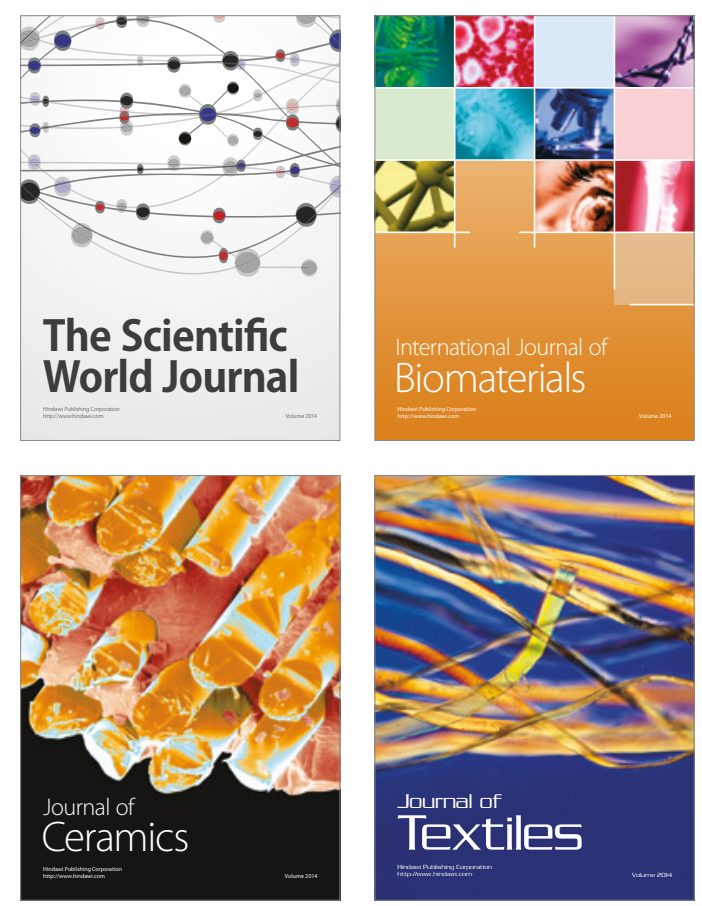